Atıf için / For Citation: M. Koç, "Ultrasonik sprey piroliz ile üretilen $\mathrm{ZnO}$ ince filmlerin alttaş sıcaklıklarının yapısal ve optik özelliklerine etkisi”, Süleyman Demirel Üniversitesi Fen Edebiyat Fakültesi Fen Dergisi, 16(1), 169-178, 2021.

\title{
Ultrasonik Sprey Piroliz ile Üretilen ZnO İnce Filmlerin Alttaş Sıcaklıklarının Yapısal ve Optik Özelliklerine Etkisi
}

\author{
Murat $\mathrm{KOÇ}^{* 1}$ \\ ${ }^{1}$ Isparta Uygulamalı Bilimler Üniversitesi, Teknik Bilimler MYO, Elektrik ve Enerji Bölümü, Nükleer \\ Teknoloji ve Radyasyon Güvenliği Programı, Isparta, 32100, Türkiye \\ *yazışılan yazar e-posta: muratkoc@isparta.edu.tr
}

(Alınış / Received : 07.04.2021, Kabul / Accepted : 28.04.2021, Yayımlanma / Published: 27.05.2021)

Özet: $\mathrm{Bu}$ çalışmada, $\mathrm{ZnO}$ ince filmler; 350,400 ve $450{ }^{\circ} \mathrm{C}$ üç farklı sıcaklıktaki alttaşa ultrasonik sprey piroliz yöntemi ile biriktirilmiştir. $\mathrm{ZnO}$ ince film üretiminde çinko kaynağ olarak çinko asetat dihidrat $\left(\mathrm{Zn}\left(\mathrm{CH}_{3} \mathrm{COO}\right)_{2} .2 \mathrm{H}_{2} \mathrm{O}\right)$ kullanılmıştır. Yapılan XRD analizleri, $\mathrm{ZnO}$ ince filmlerin, nano boyutta hekzagonal yapıda ve baskın pik pozisyonunun (100) düzleminde olduğunu doğrulamıştır. Kristal tane boyutu Debye-Scherrer formülü kullanılarak hesaplanmış ve 324.7-442.3 $\AA$ aralığında bulunmuştur. SEM yüzey görüntüleri incelendiğinde $\mathrm{ZnO}$ ince filmlerin homojen bir şekilde kaplandığı ve SEM kesit görüntülerinden kalınlıkların 251-286 nm aralığında değiştiği görülmektedir. Filmlerin yüzey pürüzlülüğü AFM ile incelenmiş ve yüzey pürüzlülük değerleri $23.00-43.44 \mathrm{~nm}$ aralığında elde edilmiştir. $\mathrm{ZnO}$ ince filmlerin UV spektrumlarından, optik geçirgenlikleri \%80' in üzerinde bulunurken, yasak enerji aralıkları 3.13-3.26 eV olarak bulunmuştur.

Anahtar kelimeler: Ultrasonik sprey piroliz, ZnO, Yüzey morfolojisi, Alttaş sıcaklığı, Optik özellikler

\section{Effect of Substrate Temperatures on Structural and Optical Properties of $\mathrm{ZnO}$ Thin Films Produced by Ultrasonic Spray Pyrolysis}

\begin{abstract}
In this study, $\mathrm{ZnO}$ thin films were deposited at three different temperatures of 350 , 400 , and $450{ }^{\circ} \mathrm{C}$ by the ultrasonic spray pyrolysis method. Zinc acetate dihydrate $\left(\mathrm{Zn}\left(\mathrm{CH}_{3} \mathrm{COO}\right)_{2} .2 \mathrm{H}_{2} \mathrm{O}\right)$ was used as a zinc source in the production of $\mathrm{ZnO}$ thin film. XRD analysis confirmed that the $\mathrm{ZnO}$ thin films are in nano-sized hexagonal structure and the dominant peak position belongs the plane of (100). The crystal grain size was calculated using the Debye-Scherrer formula and found between 324.7-442.3 $\AA$. When SEM surface images are examined, it is seen that $\mathrm{ZnO}$ thin films have a homogeneous structure and thicknesses vary between $253-286 \mathrm{~nm}$ from SEM cross-section. The surface roughness of the films was examined with AFM, and the surface roughness values were obtained in the range of 23.00$43.44 \mathrm{~nm}$. From the UV spectra of $\mathrm{ZnO}$ thin films, optical transmittance was found to be over $80 \%$, and the forbidden bandgap energies in-between 3.13-3.26 eV.
\end{abstract}

Key words: Ultrasonic spray pyrolysis, $\mathrm{ZnO}$, Surface morphology, Substrate temperature, Optical properties 


\section{Giriș}

Görünür bölgede yüksek optik geçirgenliğe sahip olması ve düşük elektrik direnci sergilemesi nedeniyle geçirgen iletken oksit filmler, güneş pilleri, sıvı kristal ekranlar ve organik 1 şık yayan diyotlar gibi birçok opto-elektronik aygıtın bileșeni olarak kullanılmaktadır [1-3]. Opto-elektronik uygulamalarda yaygın olarak tercih edilen geçirgen iletken oksit filmler, flor katkılı kalay oksit (FTO) ve indiyum katkılı kalay oksittir (ITO) [4]. İndiyum kaynaklarının tükenmesi, kalay maliyetinin yükselmesi, ITO'nun toksik olması ve $300{ }^{\circ} \mathrm{C}$ 'nin üzerinde tavlandığında direncinin önemli derecede artması, FTO'nun ısıya dirençli olmasına rağmen yüksek direnç sergilemesi bilim insanlarını geçirgen oksit filmler için yeni arayışlara yöneltmiştir [1, 5-7]. Çinko oksit $(\mathrm{ZnO})$, düşük malzeme maliyeti, stabil olması, çözelti tabanlı olarak kolayca sentezlenmesi ve toksik olmamasından dolayı geçirgen iletken oksit film üretimi için dikkat çekici bir alternatiftir. ZnO, vurtzit altıgen yapıya sahiptir ve şeffaf özellik sergilemektedir. Aynı zamanda $\mathrm{ZnO}$, geniş direk bant aralığına (oda sıcaklığında 3.37 $\mathrm{eV})$, yüksek bağlanma enerjisine $(60 \mathrm{meV})$ ve yüksek elektron mobilitesine (115-155 $\mathrm{cm}^{2} \mathrm{~V}^{-1} \mathrm{~s}^{-1}$ ) sahip II-VI türü bileşik olan bir n-tipi yariiletkendir. Sahip oldukları eşsiz kimyasal ve fiziksel özelliklerinden dolayı, özellikle katkılanmış ZnO ince filmler, FTO ve ITO'ya alternatiftir [7-10]. Elektronik sanayinde, heteroeklem yapilarda [11], fotovoltaik uygulamalarda [12], UV fotoiletken fotodedektör [13], gaz sensörü [14], transistör [15] ve güneş pili [16] gibi birçok aygıtta $\mathrm{ZnO}$ ince filmler kullanılmaktadır.

Yüksek performans sergileyen kaliteli bir ince film elde etmek; katkılamaya, üretim koşullarına ve üretim tekniğine bağlıdır [9]. $\mathrm{ZnO}$ ince filmler, literatürde, termal buharlaştırma [17], sol-jel [18], RF magnetron saçtırma [19], kimyasal buhar biriktirme, [20], sprey piroliz [21] ve ultrasonik sprey piroliz [22] gibi üretim yöntemleri ile elde edilmiştir. Sprey piroliz, geniş alanda ince film biriktirmeye uygundur ve düşük maliyetlidir. Sprey piroliz yöntemi alttaş sıcaklığının, nözülün alttaşa olan mesafesinin, çözeltinin akış hızının ve oranının kontrol edilmesine imkân sağladığ 1 için çözelti tabanlı ince filmlerin elde edilmesi için oldukça uygun bir yöntemdir [8, 23]. Ultrasonik sprey piroliz (USP) yöntemi ise sprey piroliz yönteminin avantajlarının yanı sıra malzeme tasarrufu sağlayan ve oldukça kullanışlı bir kaplama tekniğidir [24, 25].

$\mathrm{Bu}$ çalışmada, $\mathrm{ZnO}$ ince filmler, USP yöntemi kullanılarak cam altlıklar üzerine çinko asetat dihidratın $\left(\mathrm{Zn}\left(\mathrm{CH}_{3} \mathrm{COO}\right)_{2} \cdot 2 \mathrm{H}_{2} \mathrm{O}\right)$ pirolizi ile biriktirilmiştir. Farklı alttaş sicaklıklarında $\left(350,400\right.$ ve $\left.450{ }^{\circ} \mathrm{C}\right)$ üretilen ve $525{ }^{\circ} \mathrm{C}$ sicaklıkta bir saat süre ile tavlanan $\mathrm{ZnO}$ ince filmlerin yapısal, morfolojik ve optik özellikleri incelenmiştir. $\mathrm{Bu}$ çalışma ile FTO ve ITO gibi maliyetli kaynak ve üretim yöntemleri problemleri olan şeffaf iletken oksitlere bir alternatif olarak $\mathrm{ZnO}$ filmlerin maliyet etkin bir yöntem olan USP yöntemi ile kontrollü bir şekilde üretilebileceği gösterilmiştir.

\section{Materyal ve Metot}

$\mathrm{ZnO}$ ince filmler, $2 \mathrm{~mm}$ kalınlığa ve $2 \times 2 \mathrm{~cm}^{2}$ yüzey alanına sahip cam altlıklar üzerine USP yöntemi ile farklı alttaş sıcaklıklarında $\left(350,400\right.$ ve $\left.450{ }^{\circ} \mathrm{C}\right)$ üretilmiştir. Cam altlıklar, inorganik ve organik kirliliklerden arındırılmak amacıyla çift distile su, etanol ve aseton ile ultrasonik olarak temizlenmiştir. Temizlenen camlar azot gazı ile kurutulmuştur.

$\mathrm{ZnO}$ üretiminde çinko kaynağı olarak çinko asetat dihidrat $\left(\mathrm{Zn}\left(\mathrm{CH}_{3} \mathrm{COO}\right)_{2} \cdot 2 \mathrm{H}_{2} \mathrm{O}\right)$, çinko nitrat hegzahidrat $\left(\mathrm{Zn}\left(\mathrm{NO}_{3}\right)_{2} \cdot 6 \mathrm{H}_{2} \mathrm{O}\right)$ ve çinko klorür $\left(\mathrm{ZnCl}_{2}\right)$ kullanılabilir $[26,27] . \mathrm{Bu}$ kaynaklar arasında $\left(\mathrm{Zn}\left(\mathrm{CH}_{3} \mathrm{COO}\right)_{2} \cdot 2 \mathrm{H}_{2} \mathrm{O}\right)$ ticari olarak yaygın bulunabilmesi, kolay kullanımı ve düşük maliyetli olması sebebiyle bu çalışmada tercih edilmiştir. $25 \mathrm{~mL}$ ve 
$0.1 \mathrm{M}\left(\mathrm{Zn}\left(\mathrm{CH}_{3} \mathrm{COO}\right)_{2} \cdot 2 \mathrm{H}_{2} \mathrm{O}\right)$ çözeltisi hazırlanmıştır. Çözücü olarak asetik asit, su, metanol (1:1:8) karışımı kullanılmıştır. Çözelti 1 saat boyunca oda sıcaklığında manyetik karıştırıcı ile karıştırılmıştır. Çözeltinin şeffaf ve homojen olduğu, çözeltide çökmenin ya da herhangi bir topaklanmanın olmadığı gözlemlenmiştir. Olası kimyasal reaksiyon aşağıdaki gibidir [9]:

$2\left[\mathrm{Zn}\left(\mathrm{CH}_{3} \mathrm{COO}\right)_{2} \cdot 2 \mathrm{H}_{2} \mathrm{O}\right]+2\left[\mathrm{CH}_{3} \mathrm{OH}\right]+2 \mathrm{O}_{2} \rightarrow 2 \mathrm{ZnO} \downarrow+4 \mathrm{H}_{2} \mathrm{O} \uparrow+5\left[\mathrm{CH}_{3} \mathrm{COOH}\right] \uparrow$

Cam altlıklar üzerine alttaş sıcaklığına bağlı $\mathrm{ZnO}$ ince filmlerin elde edilebilmesi için USP cihazında kullanılan parametreler Tablo 1'de verilmiştir.

Tablo 1. ZnO ince filmler için USP cihazında kullanılan parametreler

\begin{tabular}{ll}
\hline Parametreler & Değerler \\
\hline Alttaş sıcaklıkları & $350-400-450^{\circ} \mathrm{C}$ \\
Çözelti akış oranı & $0.5 \mathrm{~mL} / \mathrm{dk}$ \\
Nozülün alttaşa olan mesafesi & $12 \mathrm{~cm}$ \\
Nozül gaz basıncı & $1.04 \mathrm{kPa}$ \\
Sprey açısı & $90^{\circ}$ \\
Sprey nozül frekansı & $80 \mathrm{kHz}$ \\
Sprey nozül gücü & $5.33 \mathrm{~W}$ \\
\hline
\end{tabular}

Cam altlıklar üzerine USP yöntemi ile alttaş sıcaklığına bağlı olarak kaplanan $\mathrm{ZnO}$ ince filmler, kül firında $525^{\circ} \mathrm{C}$ 'de 1 saat boyunca tavlanmıştır. Tavlanan ince filmlerin X1şını kırınımı (XRD) ölçümleri, Bruker D8 Advance Twin-Twin difraktometrenin (40 $\mathrm{kV}, 40 \mathrm{~mA}) \mathrm{Cu} \mathrm{K \alpha}$ radyasyonu ( $\lambda=1.5418 \AA$ ) kullanılarak, $0.01^{\circ}$ çözünürlük ile 20-80 aralığında gerçekleştirilmiştir. Filmlerin yüzey morfolojileri taramalı elektron mikroskobu (FEI Quanta FEG 250) ile incelenirken yüzey pürüzlülükleri atomik kuvvet mikroskobu (Nanomagnetics ezAFM) ile gözlenmiştir. Optik soğurma ölçümleri, oda sicaklığında çalıştırılan UV-Vis spektrofotometre (PG-Instruments T80 +) cihazı kullanılarak oda sıcaklığında alınmıştır.

\section{Bulgular}

\subsection{Yapısal Özellikler}

350, 400 ve $450{ }^{\circ} \mathrm{C}$ 'de üç farklı alttaş sıcaklığında biriktirilen $\mathrm{ZnO}$ ince filmlerin yapısal analizleri XRD sisteminde, $2 \theta=20-80^{\circ}$ aralığ taranarak Bragg-Brentano yöntemi kullanılarak yapılmıştır. Üç farklı alttaş sıcaklığında $\left(350,400\right.$ ve $\left.450{ }^{\circ} \mathrm{C}\right)$ biriktirilen ve daha sonra $525{ }^{\circ} \mathrm{C}$ 'de tavlama işlemine tabi tutulan $\mathrm{ZnO}$ ince filmlerin $\mathrm{X}$ ışını kırınım desenleri Şekil 1 ve Şekil 2'de sırasıyla verilmiştir.

$350{ }^{\circ} \mathrm{C}$ alttaş sıcaklığında biriktirilen ve tavlama işlemine tabi tutulmayan örneğin kristal yapısının oluşmadığı ve alttaş sıcaklığının artırılması ile filmlerin kristal yapısında bir iyileşme olduğu Şekil 1'de görülmektedir. Alttaş sıcaklığının artması ile termal ayrışmanın sonucu olarak kristal yapıdaki iyileşme literatürle uyum içindedir [28]. Yeterli termal enerjiye ulaşan molekül gruplarının hem organik taşıyıcılarından (C, $\mathrm{H}$ vb.) kurtulduğu hem de enerji bakımından daha uygun bağlar yaparak kristallenmeye katkı sağladığı düşünülmüştür. Ayrıca $525{ }^{\circ} \mathrm{C}$ 'de tavlanan tüm $\mathrm{ZnO}$ ince filmler örneklerin hekzagonal yapıda olduğu görülmüştür.

$525^{\circ} \mathrm{C}^{\prime}$ de tavlama işlemine tabi tutulan $\mathrm{ZnO}$ ince filmlerin ana pikleri $2 \theta=31.737^{\circ}$, $34.379^{\circ}, 36.215^{\circ}$ ve $56.536^{\circ}$ açılarında görülmüş olup, bu açılar (100), (002), (101) ve (110) düzlemlerine karşılık gelmektedir. Kırınım desenindeki pikler, “Joint Committee 
on Powder Diffraction Standards (JCPDS) " veri tabanı ile indekslenmiştir ve 01-0891397 kart numarasina uygundur.

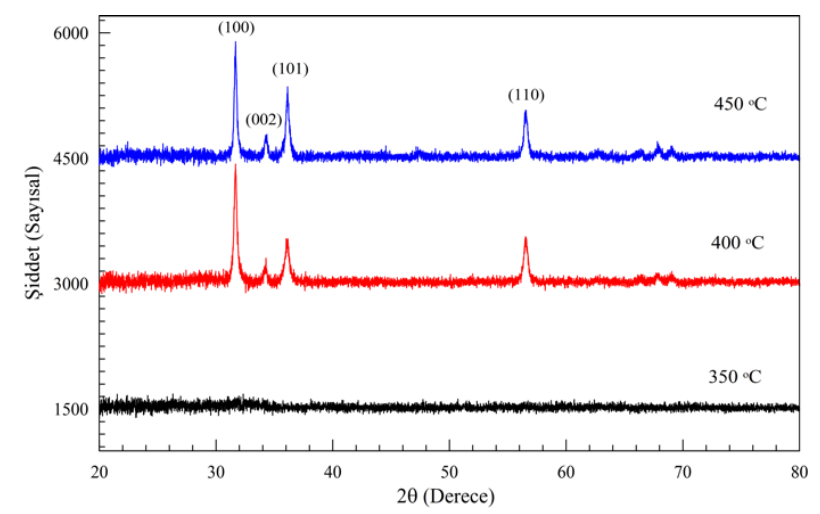

Şekil 1. 350,400 ve $450{ }^{\circ} \mathrm{C}$ alttaş sıcaklığında biriktirilen $\mathrm{ZnO}$ ince fillmlerin XRD deseni

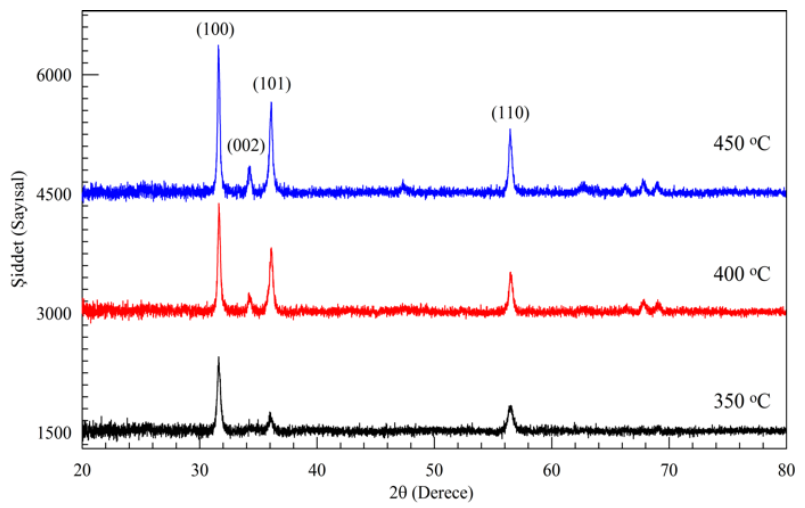

Şekil 2. $525^{\circ} \mathrm{C}^{\prime}$ de tavlanan $\mathrm{ZnO}$ ince filmlerin XRD deseni

Cam altlıklar üzerine biriktirilen $\mathrm{ZnO}$ ince filmlerin kristal boyutu $(D)$ denklem 2'de verilen Debye-Scherrer eşitliği kullanılarak hesaplanmıştır.

$$
D=K \frac{\lambda}{\beta(\cos \theta)}
$$

Burada, $\beta$ ilgili pikin maksimum yüksekliğinin yarı genişliğini (FWHM), $\mathrm{K}$ boyutsuz şekil faktörünü $(\mathrm{K}=0.94), \theta$ Bragg açısını (radyan) ve $\lambda$ kullanılan $\mathrm{X}$-1şınının dalga boyunu (1.5418 $\AA$ ) göstermektedir.

$\mathrm{ZnO}$ ince filmlerin kristal boyutu Tablo 2'de verilmiştir. Tablo 2'de görüldügü gibi alttaş sıcaklığının artması ile kristal boyutunda artma gözlenmiş ve en yüksek kristal boyutu $450{ }^{\circ} \mathrm{C}$ alttaş sıcaklığında üretilen $\mathrm{ZnO}$ ince film için $442.3 \AA$ olarak ölçülmüştür. Bu sonuç daha önce yapılan çalışma ile uyum içerisindedir [28].

Tablo 2. USP ile biriktirilmiş ve $525^{\circ} \mathrm{C}$ 'de tavlanan $\mathrm{ZnO}$ ince filmlerin kristal boyutun farklı alttaş sıcaklıklarına bağlı olarak değişimi

\begin{tabular}{cc}
\hline Sicaklık $\left({ }^{\circ} \mathbf{C}\right)$ & Kristal Boyut $(\mathbf{D})(\AA)$ \\
\hline 350 & 324.7 \\
400 & 385.7 \\
450 & 442.3 \\
\hline
\end{tabular}


Kristal boyutlardaki artışın; $\mathrm{ZnO}$ ince filmlerin direncinde bir azalma ile sonuçlandığı Mahmoud ve Kiriakidis tarafından yapılan daha önceki çalışmada bildirilmiştir [29].

\subsection{Morfolojik Özellikler}

350, 400 ve $450{ }^{\circ} \mathrm{C}$ alttaş sıcaklıklarında biriktirilen ve $525{ }^{\circ} \mathrm{C}$ sıcaklıkta bir saat tavlanan ZnO filmlerin yüzey ve kesit SEM görüntüleri Şekil 3 ve Şekil 4'te sırasıyla verilmiştir. Farklı alttaş sıcaklıklarında yapılan $\mathrm{ZnO}$ ince film kaplamaların homojen bir yapıya sahip olduğu, Şekil 3 'te verilen $\times 100000$ büyütme oranındaki SEM yüzey görüntüleri ile gösterilmiştir. $350{ }^{\circ} \mathrm{C}$ 'de biriktirilen $\mathrm{ZnO}$ ince filmlerin nano-çubuk şeklinde oluştuğu Şekil 3a'da görülmektedir. Alttaş sıcaklığının artması ile nanoçubukların birbirlerine bağlanmaları artmış ve sıcaklığın sonucu olarak nano boyuttaki boşluklar kapanmıştır. Artan sıcaklıkla daha homojen bir yapıya dönüşen $\mathrm{ZnO}$ ince filmlerin yüzey pürüzlülügünde de $(\mathrm{Ra})$ artma meydana gelmiştir. $\mathrm{Bu}$ sonucu Atomik Kuvvet Mikroskobu (AFM) ile yapılan Ra ölçümü desteklemektedir.
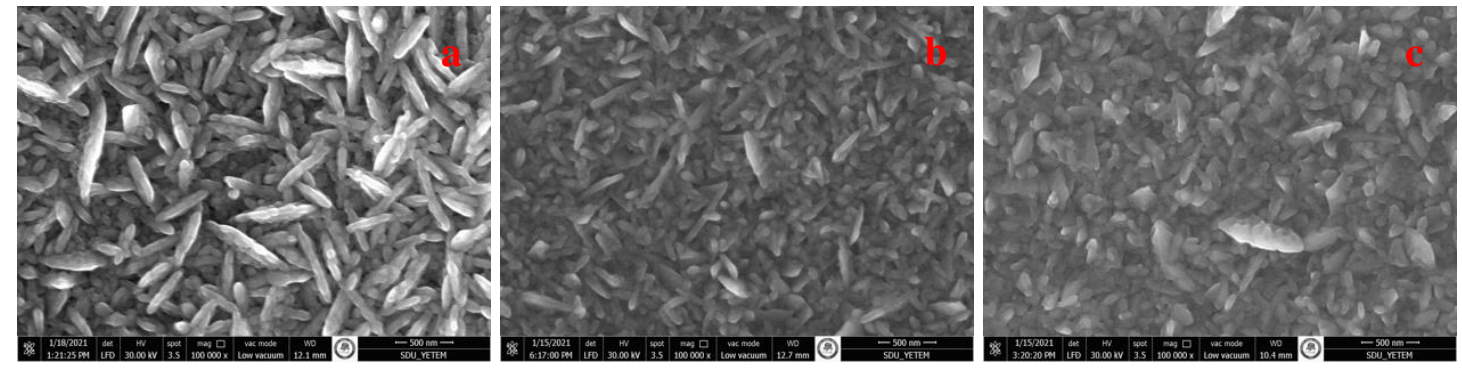

Şekil 3. Farklı alttaş sıcaklıklarında biriktirilen (a) $350{ }^{\circ} \mathrm{C}$, b) $400{ }^{\circ} \mathrm{C}$ ve c) $450{ }^{\circ} \mathrm{C}$ ) ve $525{ }^{\circ} \mathrm{C}$ sıcaklıkta tavlanan $\mathrm{ZnO}$ filmlerin yüzey görüntüleri
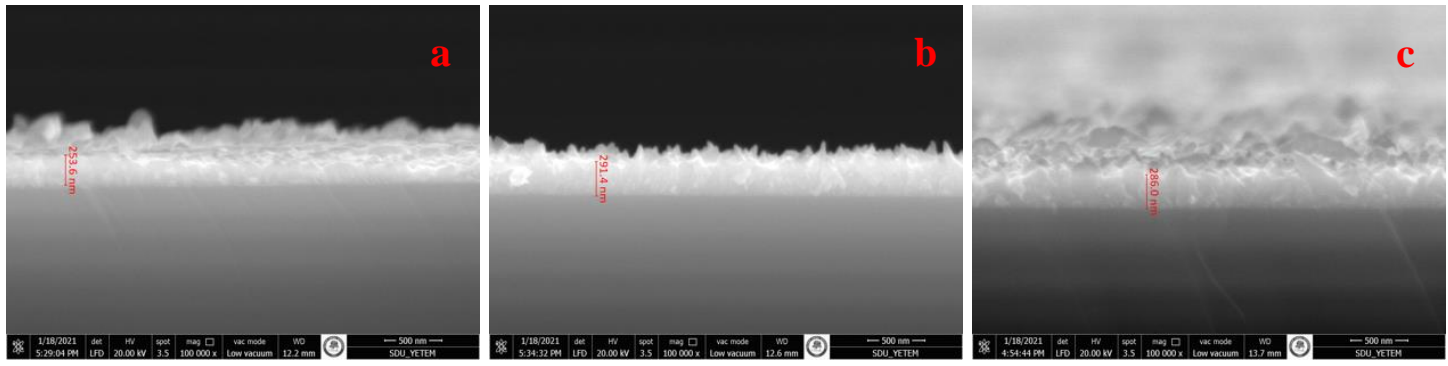

Şekil 4. Farklı alttaş sıcaklıklarında biriktirilen (a) $350{ }^{\circ} \mathrm{C}$, b) $400{ }^{\circ} \mathrm{C}$ ve c) $450{ }^{\circ} \mathrm{C}$ ) ve $525^{\circ} \mathrm{C}$ sıcaklıkta tavlanan $\mathrm{ZnO}$ filmlerin kesit görüntüleri

Kesit görüntülerinde film kalınlıkları 350, 400 ve $450{ }^{\circ} \mathrm{C}$ alttaş sıcaklıkları için sırasıyla $251 \pm 10,289 \pm 15$ ve $286 \pm 09 \mathrm{~nm}$ olarak ölçülmüştür. $350{ }^{\circ} \mathrm{C}$ alttaş sicaklığında biriktirilen $\mathrm{ZnO}$ ince filmlerde amorf fazdan kristal faza geçişi tam olarak gerçekleşmediğinden film kalınlığı 400 ve $450^{\circ} \mathrm{C}$ alttaş sıcaklıklarındaki filmlere göre daha düşüktür. Alttaş sıcaklığının $400{ }^{\circ} \mathrm{C}$ 'den $450{ }^{\circ} \mathrm{C}$ 'ye çıkmasıyla kalınlığın azaldığ 1 gözlenmiştir.

İnce filmlerin yüzey morfolojisi hakkında bilgi veren diğer bir yöntem ise AFM analizidir. Farklı alttaş sıcaklıklarında biriktirilen $\left(350,400\right.$ ve $\left.450{ }^{\circ} \mathrm{C}\right)$ ve $525{ }^{\circ} \mathrm{C}$ sicakl1kta tavlanan $\mathrm{ZnO}$ filmlerin AFM yüzey görüntüleri Şekil 5’te verilmiştir.

AFM analizi ile 350,400 ve $450{ }^{\circ} \mathrm{C}$ üç farklı alttaş sıcaklığı için ortalama yüzey pürüzlülük değerleri sirasıyla, 23.00, 24.63, ve $43.44 \mathrm{~nm}$ olarak belirlenmiştir. Yüzey pürüzlülüğ̈̈nün, alttaş sıcaklığının artması ile artması Swapna ve Kumar tarafindan yapılan çalışma ile uyum içindedir [30]. Ortalama yüzey pürüzlülük değerlerinden de anlaşılacağı üzere alttaş sıcaklığının artması ve tavlamanın etkisi ile Ra değeri artmıştır. 
Özellikle $450{ }^{\circ} \mathrm{C}$ 'de pürüzlülüğün neredeyse iki katına çıktığı görülmektedir. Alttaş sıcaklığının artması ile Ra değerindeki değişimin, XRD analizi ile verilen kristal boyutlarındaki değişimle uyum içinde olduğu görülmüş̧ür.
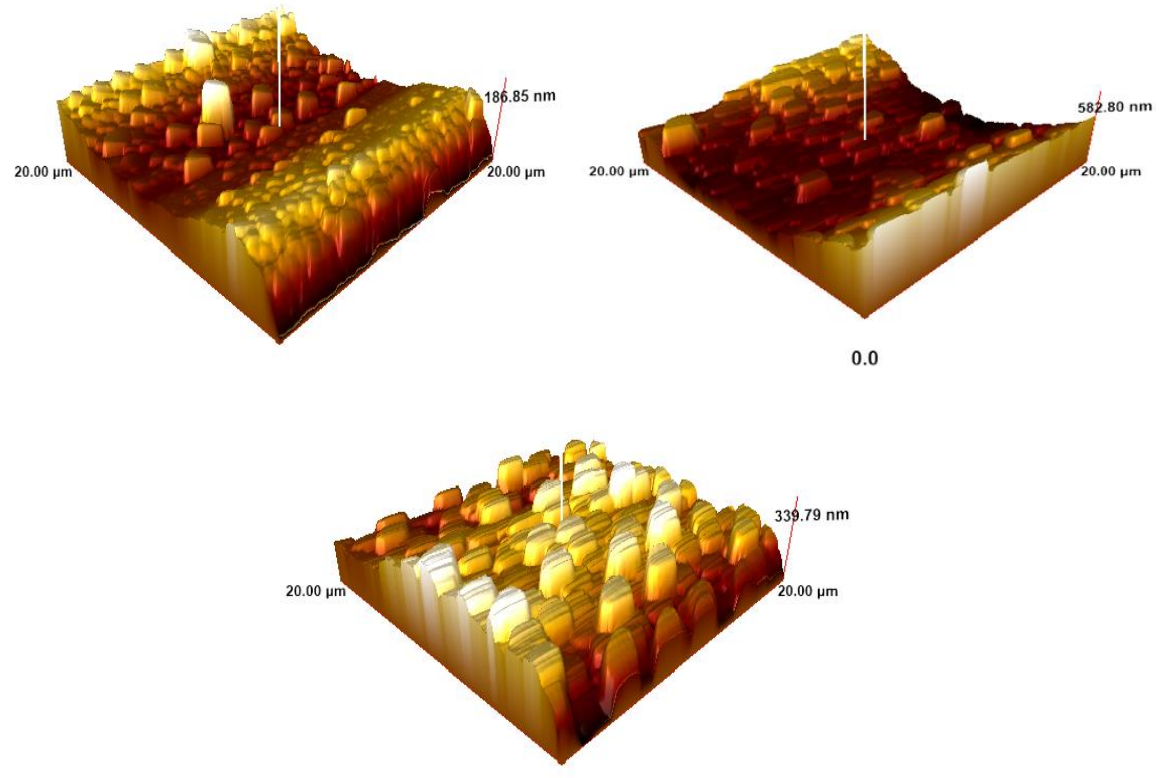

Şekil 5. Farklı alttaş sıcaklıklarında biriktirilen (a) $350{ }^{\circ} \mathrm{C}$, b) $400{ }^{\circ} \mathrm{C}$ ve c) $450{ }^{\circ} \mathrm{C}$ ) ve $525{ }^{\circ} \mathrm{C}$ sıcaklıkta tavlanan $\mathrm{ZnO}$ filmlerin AFM yüzey görüntüleri

\subsection{Optik Özellikler}

Şekil 6a ve $6 \mathrm{~b}$, farklı alttaş sıcaklıklarında $\left(350,400\right.$ ve $\left.450^{\circ} \mathrm{C}\right)$ cam üzerine biriktirilen ve $525^{\circ} \mathrm{C}$ 'de tavlanan $\mathrm{ZnO}$ filmlerinin geçirgenlik spektrumlarını göstermektedir. Tüm $\mathrm{ZnO}$ ince film örnekler, görünür bölgede, \%80'den daha fazla geçirgenlik göstermiştir. $\mathrm{ZnO}$ ince filmlerin yasak enerji aralıkları, yakın ultraviyole bölgeye ( 350-380 nm) karşılık geldiği için bu bölgede güçlü bir bozulma gösterir [31]. Şekil 6a'da tavlama işlemine tabi tutulmayan $\mathrm{ZnO}$ ince filmlerin geçirgenlikleri, Şekil 6b'de tavlama işlemine tabi tutulan $\mathrm{ZnO}$ ince filmlerin geçirgenliklerine kıyasla daha yüksek olduğu görülmektedir.
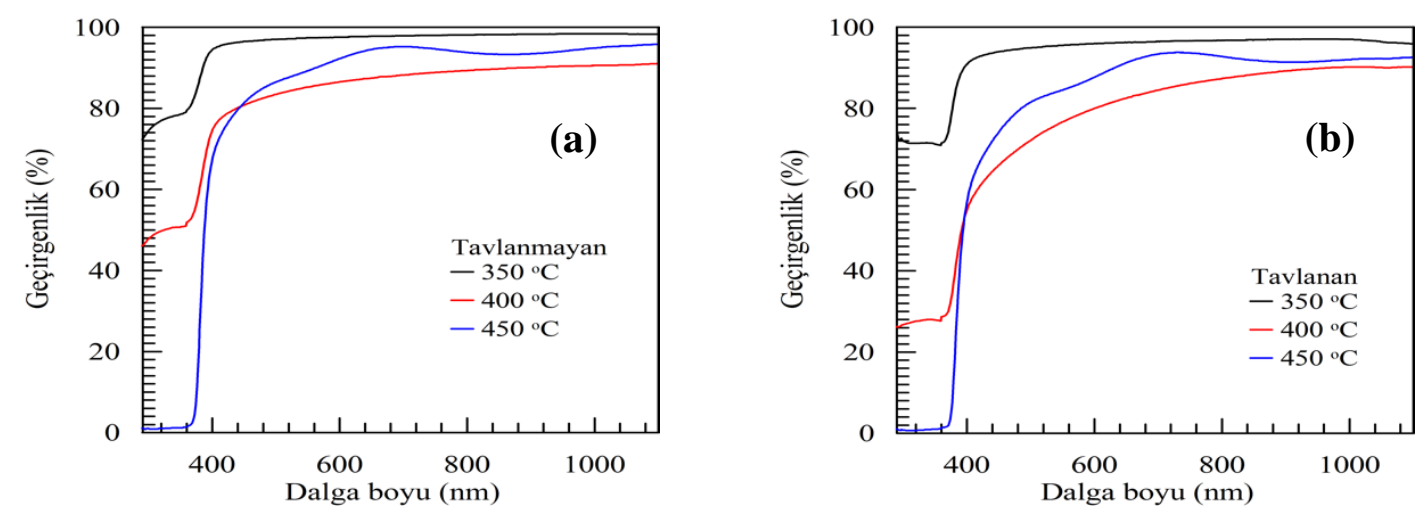

Şekil 6. Farklı alttaş sıcaklıklarında biriktirilen (a) 350,400 ve $450{ }^{\circ} \mathrm{C}$ ve (b) $525^{\circ} \mathrm{C}$ sıcaklıkta tavlanan $\mathrm{ZnO}$ filmlerin geçirgenlik spektrumu

$\mathrm{ZnO}$ ince filmlerin geçirgenlik spektrumlarından anlaşılacağı üzere, en yüksek geçirgenlik $350{ }^{\circ} \mathrm{C}$ alttaş sicaklığında biriktirilen örnekte görülürken, en düşük 
geçirgenlik ise $450{ }^{\circ} \mathrm{C}$ alttaş sicaklığında biriktirilen örnektedir. $350{ }^{\circ} \mathrm{C}$ alttaş sıcaklığında biriktirilen $\mathrm{ZnO}$ ince filmin daha iyi optik geçirgenliğe sahip olmasının daha küçük yüzey pürüzlülüğün sonucu olduğu düşünülmektedir.

$\mathrm{ZnO}$ ince filmlerin yasak enerji aralığı $\left(\mathrm{E}_{\mathrm{g}}\right)$ denklem 3'te verilen Tauc eşitliği kullanılarak hesaplanmıştır.

$$
\alpha \mathrm{h} v=\mathrm{K}\left(\mathrm{h} v-E_{g}\right)^{m}
$$

Burada $\alpha$, soğurma katsayısı, $h$, Planck sabiti, $v$, foton frekansı, $K$, bir sabit ve $m$ ince filmin optik geçiş türüne (direkt- endirekt) ait bir katsayıdır [32]. Şekil 7'de, ZnO ince filmlerin $(\alpha h v)^{2}$ 'nin $h v^{\prime}$ 'ye karşı çizilen grafikleri görülmektedir. $\mathrm{ZnO}$ ince filmlerin yasak enerji aralığı değerini elde etmek için ekstrapolasyon yöntemi kullanılmıştır.

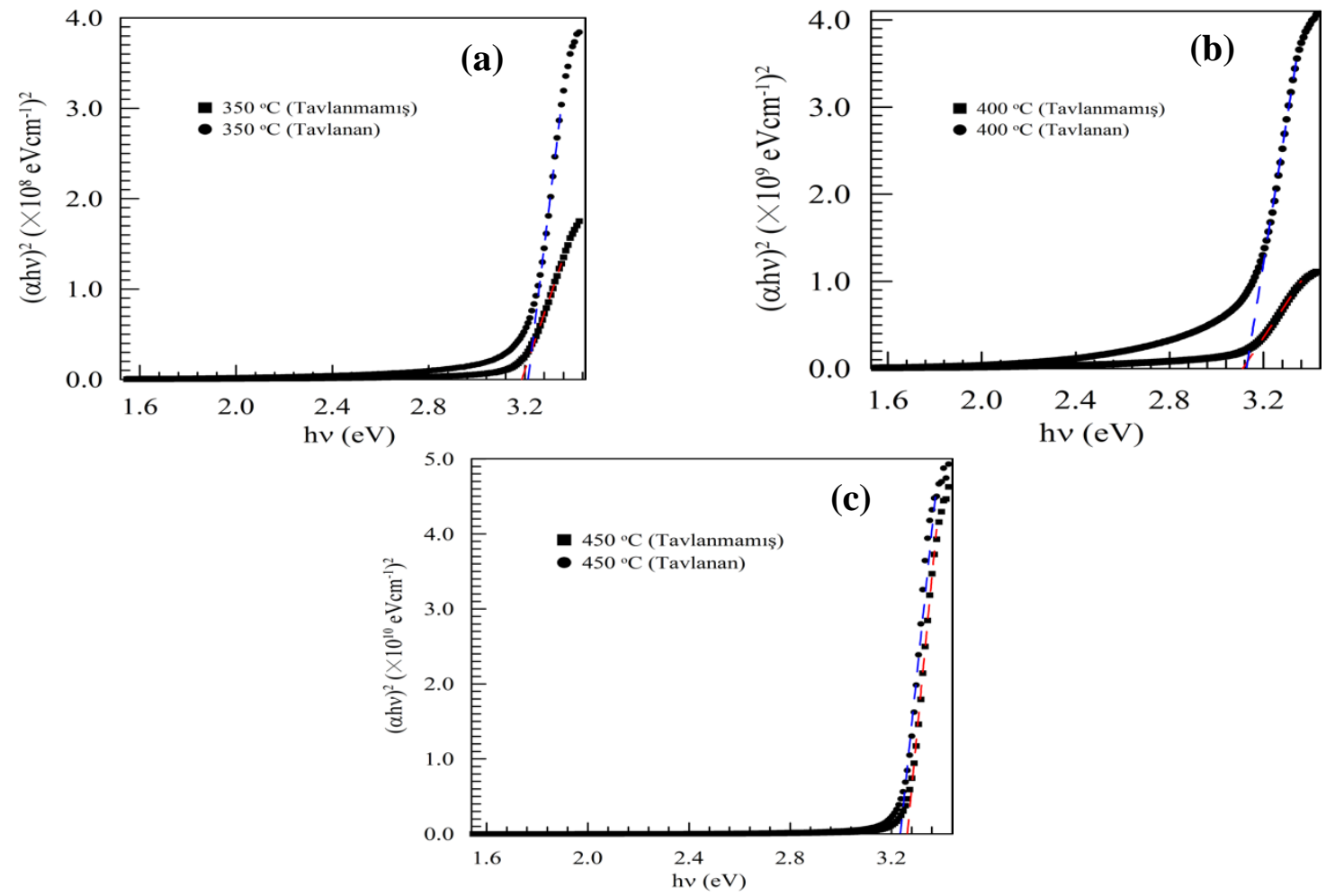

Şekil 7. Farklı alttaş sıcaklıklarında biriktirilen tavlanmamış-tavlanmış $\mathrm{ZnO}$ ince film örneklerinin $(\alpha h v)^{2}$ 'nin hv'ye karşı grafikleri ve ekstrapolasyon yöntemiyle bulunan yasak enerji $\left(\mathrm{E}_{\mathrm{g}}\right)$ değerleri

Ekstrapolasyon yöntemi ile hesaplanan filmlerin yasak enerji aralıkları Tablo 3'te verilmiştir. $\mathrm{ZnO}$ ince filmlerin yasak enerji aralıkları, $\mathrm{E}_{\mathrm{g}}$, alttaş sıcaklığına ve tavlamanın etkisine bağlı olarak 3.13-3.26 eV aralığında değişmektedir.

Tablo 3. Farklı alttaş sıcaklarında biriktirilen $\mathrm{ZnO}$ ince filmlerin yasak enerji $\left(\mathrm{E}_{\mathrm{g}}\right)$ değerleri

\begin{tabular}{ccc}
\hline $\begin{array}{c}\text { Alttaş S1caklığ } 1 \\
\left({ }^{\circ} \mathrm{C}\right)\end{array}$ & $\begin{array}{c}\text { Tavlanmayan } \\
\mathrm{E}_{\mathrm{g}}(\mathrm{eV})\end{array}$ & $\begin{array}{c}\text { Tavlanan }\left(525^{\circ} \mathrm{C}\right) \\
\mathrm{E}_{\mathrm{g}}(\mathrm{eV})\end{array}$ \\
\hline 350 & 3.19 & 3.21 \\
400 & 3.19 & 3.13 \\
450 & 3.26 & 3.25 \\
\hline
\end{tabular}

Rahal ve arkadaşları tarafından USP yöntemiyle farklı alttaş sıcaklıklarında biriktirilen $\mathrm{ZnO}$ ince filmlerinin yasak enerji aralıklarının, alttaş sıcaklığının artması ile azaldığı rapor edilmiştir [33]. Ancak yapılan bu çalışma, alttaş sıcaklığının artmasıyla $\mathrm{ZnO}$ ince filmlerin yasak enerji aralığında bir düşüş olduğunu göstermektedir. Diğer taraftan tavlamanın etkisiyle yasak enerji Eg'nin artacağı Aoun ve arkadaşları tarafindan yapılan çalışmada rapor edilmiştir [34]. Yapılan bu çalışmada alttaş sıcaklığına ve tavlama sicaklığına bağlı olarak net bir sonuç görülmemektedir. Ancak $350{ }^{\circ} \mathrm{C}$ alttaş 
sicaklığında biriktirilen ve daha sonra $525{ }^{\circ} \mathrm{C}$ 'de tavlanan $\mathrm{ZnO}$ ince filmin $\mathrm{E}_{\mathrm{g}}$ değerindeki değişim literatürle benzerdir [33-34]. 400 ve $450{ }^{\circ} \mathrm{C}$ alttaş sıcaklıklarında biriktirilen ve daha sonra $525{ }^{\circ} \mathrm{C}$ 'de tavlanan $\mathrm{ZnO}$ ince filmlerin $\mathrm{E}_{\mathrm{g}}$ yasak enerji aralıklarının benzer eğilimde olduğu görülmektedir.

\section{Sonuç ve Yorum}

Ultrasonik sprey piroliz yöntemi ile yapılan bu çalışmada, farklı alttaş sıcaklıklarının $\left(350,400\right.$ ve $450{ }^{\circ} \mathrm{C}$ ) ve $525{ }^{\circ} \mathrm{C}$ tavlama sıcaklığının $\mathrm{ZnO}$ ince filmler üzerine yapısal, morfolojik ve optik özellikleri üzerindeki etkisi araştırılmıştır. ZnO ince filmlerinin XRD spektrumu, $350{ }^{\circ} \mathrm{C}$ alttaş sıcaklığında biriktirilen filmin kristal yapısının oluşmadığını, ancak alttaş sıcaklığının artması ve $525{ }^{\circ} \mathrm{C}$ tavlama ile kristal yapının $\mathrm{ZnO}$ krsitaline uyduğunu göstermektedir. Ayrıca XRD sonucu, filmlerin hekzagonal yapıda ve kristal tane boyutlarının 324.7-442.3 $\AA$ aralığında olduğunu göstermektedir. $\mathrm{ZnO}$ ince filmlerin yüzey morfolojileri incelendiğinde kaplamların homojen bir yapıya sahip olduğu, alttaş sıcaklığının artması ile nano-çubukların birbirlerine bağlanmalarının arttığı ve boşluklar kapandığı görülmüştür. Sıcaklığın artmasıyla filmlerin yüzey pürüzlülüğünde de $(\mathrm{Ra})$ artma gözlemlenmiştir. $\mathrm{ZnO}$ ince filmlerin tamamı, görünür bölgede \%80'in üzerinde geçirgenlik göstermiştir. Tavlama işlemine tabi tutulan filmlerin geçirgenliğinde bir miktar azalma gözlenmiştir. $\mathrm{ZnO}$ ince filmlerin, farklı alttaş sıcaklığı ve tavlamanın etkisiyle, yasak enerji değerlerinin $\left(\mathrm{E}_{\mathrm{g}}\right)$ 3.13-3.26 eV aralığında değiştiği görülmüştür.

\section{Araştırmacıların Katkı Oranı Beyanı}

Murat KOÇ Araştırma, Deneysel Süreci Yürütme, Yazım, Doğrulama, İnceleme ve Düzenleme

\section{Çatışma Beyanı}

Bu çalışmanın yazarları olarak beyan edecek bir çıkar çatışmamız yoktur.

\section{Etik Kurul Onayı ve Aydınlatılmış Onam Bilgileri}

$\mathrm{Bu}$ çalışmanın yazarları olarak herhangi bir etik kurul onayı ve/veya aydınlatılmış onam bilgileri beyanımızın bulunmadığını bildiririz. 


\section{Kaynakça}

[1] C. H. Lai, Z. Y. Lee, S. C. Lin, and Y. H. Chuang, "Al-doped ZnO transparent conducting glass with an IGZO buffer layer for dye-sensitized solar cells," IEEE J Photovolt, 10 (3), 795-802, 2020.

[2] A. K. Sahoo, C. S. Yang, O. Wada, and C. L. Pan, "Twisted nematic liquid crystal based terahertz phase shifter with crossed indium tin oxide finger type electrodes," IEEE Trans. Terahertz Sci. Technol, 9 (4), 399-408, 2019.

[3] D. Saikia, and R. Sarma, "A comparative study of the influence of nickel oxide layer on the FTO surface of organic light emitting diode," Indian J. Phys., 92 (3), 307-313, 2018.

[4] T. Kawashima, H. Matsui, and N. Tanabe, "New Transparent Conductive Films: FTO Coated ITO," Thin Solid Films, 445 (2), 241-244, 2003.

[5] D. A. Keller, H. N. Barad, E. Rosh-Hodesh, A. Zaban, and D. Cahen, "Can fluorine-doped tin oxide, FTO, be more like indium-doped tin oxide, ITO? Reducing FTO surface roughness by introducing additional $\mathrm{SnO}_{2}$ coating," Mrs Commun., 8 (3), 1358-1362, 2018.

[6] T. V. Dang, S. V. N. Pammi, J. Choi, and S. G. Yoon, "Utilization of AZO/Au/AZO multilayer electrodes instead of FTO for perovskite solar cells," Sol. Energy Mater. Sol. Cells, 163, 58-65, 2017.

[7] A. Andersson, N. Johansson, P. Bröms, N. Yu, D. Lupo, and W. R. Salaneck, "Fluorine tin oxide as an alternative to indium tin oxide in polymer LEDs," Adv. Mater., 10 (11), 859-863, 1998.

[8] S. J. Ikhmayies, "Spray-deposited coral-like $\mathrm{ZnO}$ micro/nano thin films on glass substrates," JOM, 73(1), 356-363, 2021

[9] N. Guermat, W. Daranfed, and K. Mirouh, "Extended wide band gap amorphous ZnO thin films deposited by spray pyrolysis," Ann Chimie Sci Materiaux, 44 (5), 347-352, 2020.

[10] Y. Benkhetta, A. Attaf, H. Saidi, R. Messemeche, A. Bouhdjer, H. Bendjedidi, I.B. Kherkhachi, and A. Rahil, "Controlling of c-axis position of $\mathrm{ZnO}$ nano-crystalline films deposited at various substrate temperature by ultrasonic spray method," Surf. Interfaces, 21, 100698, 2020.

[11] H. Trir, L. Radjehi, N. Sengouga, T. Tibermacine, L. Arab, W. Filali, D. Abdelkader, and N. Attaf, "Effect of annealing on the dark and illuminated $\mathrm{I}(\mathrm{V})$ characterization of a $\mathrm{ZnO}: \mathrm{Ga} \mid \mathrm{Cu}_{2} \mathrm{O}$ heterojunction prepared by ultrasonic spray system," Semiconductors, 54, 534-542, 2020.

[12] T. Potlog, L. Gorceac, M. Taku, I. Lungu, S. Raevschi, S. Worasawat, V. Botnariuc, and H. Mimura, "Synthesis and properties of Al-doped ZnO thin films for photovoltaics," In 2018 4th ICNERE, IEEE, 1-6, 2018.

[13] M. Acosta-Osorno, S. Alcántara-Iniesta, J. Alvarado, C. D. Young, I. Mejía, M. García, J.R. RamosSerrano, and G. Juarez-Díaz, "Characterization of $\mathrm{ZnO}$ thin films obtained by ultrasonic spray pyrolysis for application in uv photoconductive detectors," Mater. Res. Express, 6(11), 116450, 2019.

[14] P. S. Kolhe, A. B. Shinde, S. G. Kulkarni, N. Maiti, P. M. Koinkar, and K. M. Sonawane, "Gas sensing performance of $\mathrm{Al}$ doped $\mathrm{ZnO}$ thin film for $\mathrm{H}_{2} \mathrm{~S}$ detection," J. Alloys Compd., 748, 6-11, 2018.

[15] G. R. Lima, J. P. Braga, G. Gozzi, and L. Fugikawa-Santos, “On the reproducibility of spray-coated ZnO thin-film transistors," Mrs Advances, 5 (35), 1859-1866, 2020.

[16] N. Kumari, S. R. Patel, and J. V. Gohel, "Optical and structural properties of ZnO thin films prepared by spray pyrolysis for enhanced efficiency perovskite solar cell application," Opt. Quantum Electron., 50 (4), 1-22, 2018.

[17] L. S. Chuah, H. I. Abdulgafour, and Z. Hassan, "Preparation of aluminum foil-supported $\mathrm{ZnO}$ nanocoral reef films," The IJES, 2, 42-45, 2013.

[18] K. Davis, R. Yarbrough, M. Froeschle, J. White, and H. Rathnayake, "Band gap engineered zinc oxide nanostructures via a sol-gel synthesis of solvent driven shape-controlled crystal growth," Rsc Advances, 9 (26), 14638-14648, 2019.

[19] M. Bouderbala, S. Hamzaoui, B. Amrani, A. H. Reshak, M. Adnane, T. Sahraoui, and M. Zerdali, "Thickness dependence of structural, electrical and optical behaviour of undoped $\mathrm{ZnO}$ thin films," Physica B. Condens. Matter, 403 (18), 3326-3330, 2008.

[20] M. G. Faraj, and K. Ibrahim, "Optical and structural properties of thermally evaporated zinc oxide thin films on polyethylene terephthalate substrates," Int. J. Polym. Sci., 2011, 1-4, 2011.

[21] S. P. Bharath, K. V. Bangera, and G. K. Shivakumar, "Enhanced gas sensing properties of indium doped ZnO thin films," Superlattices Microstruct., 124, 72-78, 2018.

[22] Y. Lee, H. Kim, and Y. Roh, "Deposition of $\mathrm{ZnO}$ thin films by the ultrasonic spray pyrolysis technique," Jpn J Appl Phys, 40 (4R), 2423, 2001.

[23] M. P. F. de Godoy, L. K. S. de Herval, A. A. C. Cotta, Y. J. Onofre, and W. A. A. Macedo, "ZnO thin films design: the role of precursor molarity in the spray pyrolysis process," J. Mater. Sci. Mater. Electron., 31 (20), 17269-17280, 2020. 
[24] W. Yang, Z. Yang, D. Li, X., Zhang, Z. Zhou, S. Tian, Y. Tong, C. Xia, M. Liu, L. Li, and F. Wang, "Study on the growth and optical properties of $\mathrm{ZnO}$ thin films fabricated by ultrasonic spray pyrolysis," Mod. Phys. Lett. B, 32 (29), 1850351, 2018.

[25] S. Akyürekli, M. Kaleli, M. Koç, D. A. Aldemir, "Ultrasonik sprey piroliz yöntemi ile üretilen güneş soğurucu $\mathrm{CH} 3 \mathrm{NH} 3 \mathrm{PbI} 3-\mathrm{xClx}$ perovskit yapısının optik, morfolojik ve yapısal özelliklerinin incelenmesi," Süleyman Demirel Üniv. FEF Derg., 15 (2), 253-263, 2020.

[26] D. Gültekin, F. Kayış, H. Akbulut, "ZnO ince film kaplamaların kıvrımlı ağ morfolojisinin incelenmesi,” Bilecik Şeyh Edebali Üniv. Fen Bilim. Derg., 3 (1), 25-28, 2016.

[27] B. I. Lahlouh, S. J. Ikhmayies, H. K. Juwhari, "Structural, optical, and vibrational properties of ZnO microrods deposited on silicon substrate," J. Electron. Mater., 47(8), 4455-4462, 2018.

[28] E. Karaköse, and H. Colak, "Effect of substrate temperature on the structural properties of $\mathrm{ZnO}$ nanorods," Energy, 141, 50-55, 2017.

[29] F. A. Mahmoud, and G. Kiriakidis, "Nanocrystalline ZnO thin film for gas sensor application," $J$ Ovonic Res., 5, 15-20, 2009.

[30] R. Swapna, and M. S. Kumar, "The role of substrate temperature on the properties of nanocrystalline Mo doped ZnO thin films by spray pyrolysis," Ceram. Int., 38(5), 3875-3883, 2012.

[31] H. Nanto, T. Minami, S. Shooji, and S. Takata, "Electrical and optical properties of zinc oxide thin films prepared by rf magnetron sputtering for transparent electrode applications," Int. J. Appl. Phys., 55 (4), 1029-1034, 1984.

[32] H. K., Kaplan ve S. K. Akay, "ZnSe/Si heteroeklem yapının fotoelektrik özelliklerinin incelenmesi," Uludağ University JFE, 24 (1), 265-276, 2019.

[33] A. Rahal, S. Benramache, and B. Benhaoua, "Substrate temperature effect on optical property of ZnO thin films," Eng. J., 18 (2), 81-88, 2014.

[34] Y. Aoun, B. Benhaoua, S. Benramache, and B. Gasmi, "Effect of annealing temperature on structural, optical and electrical properties of zinc oxide $(\mathrm{ZnO})$ thin films deposited by spray pyrolysis technique," Optik, 126 (24), 5407-5411, 2015. 